\title{
APLIKASI PROGRAM QUALITY CONTROL BARANG UNTUK MENUNJANG PELAPORAN PADA BAGIAN TEKNIK PERGURUAN TINGGI RAHARJA
}

\author{
Aris $^{1}$, Tiya Puspita Firdaus ${ }^{2}$, Nesa Nurseha ${ }^{3}$ \\ ${ }^{1}$ Dosen AMIK Raharja Jurusan Teknik Informatika, ${ }^{2,3}$ Mahasiswa STMIK Raharja Jurusan Sistem \\ Infromasi \\ 1,2,3J1.Jendral Sudirman No.40, Modern Cikokol, Tangerang \\ e-mail: ${ }^{1}$ aris@raharja.info, ${ }^{2}$ tiya@ raharja.info, ${ }^{3}$ nesa@ raharja.info
}

\begin{abstract}
Abstrak
Sistem pengolahan data Perguruan Tinggi Raharja membutuhkan yang terbaik dan terintegrasi untuk memudahkan pengambilan keputusan dan menciptakan standar pelayanan yang baik. Apalagi jika data terkait dengan Kontrol dan Kualitas. Data dan informasi mudah diakses sangat dibutuhkan untuk mendukung kinerja masing-masing bagian. Seperti pada bagian Teknik, Dalam pengolahan data bagian teknik masih belum dapat memberikan layanan terbaik untuk memenuhi kebutuhan informasi strategis yang diperlukan untuk mendukung pelaporan pada manajemen Perguruan Tinggi Raharja. Dibutuhkan waktu yang lama untuk menghasilkan informasi data barang seperti yang diperlukan, hal ini terjadi karena belum terintegrasi dengan manajemen dan pengolahan informasi belum dapat efektif dan efisien, Dengan metode perancangan menggunakan UML, serta pembuatan program aplikasi menggunakan bahasa pemograman PHP berbasis website .Sehingga dapat membantu dalam pelaporan data barang secara online oleh bagian teknik untuk manajemen yang dapat meningkatkan kinerja bagian teknik untuk Manajemen Perguruan Tinggi Raharja sehingga memberikan pelayanan yang baik dan lebih cepat.
\end{abstract}

Kata kunci: Sistem, Aplikasi, Kualitas, Kontrol

\begin{abstract}
Data processing system of Higher Education Raharja needs the best and integrated to facilitate decision making and create good service standard. Especially if the data is related to Control and Quality. Data and information easily accessible to support the performance of each section. As in the Engineering section, In data processing Engineering section still can not provide the best service to meet the strategic information needs required to support reporting on the management of Higher Education Raharja. It takes a long time to generate information data items as required, this happens because it has not been integrated with the management and information processing can not be effective and efficient, With the design method using UML, as well as making the application program using PHP programming language website based .So can help in reporting data goods engineering section for management that can improve the performance of engineering section for Higher Education Raharja so as to provide good and faster service.
\end{abstract}

Keywords: System, Application, Quality, Control 


\section{PENDAHULUAN}

Dengan berkembangnya teknologi pada saat ini khususnya di bidang komputer sangat mempengaruhi kinerja baik pada instansi-instansi pemerintah, perguruan tinggi maupun perusahaanperusahaan swasta. Komputer sangat berperan penting dalam menunjang kelancaran terlaksananya kegiatan operasional serta tercapainya keberhasilan pada sebuah perusahaan. Hal ini dapat ditingkatkan melalui peningkatan sistem informasi. Penggunaan komputer dalam sistem informasi juga tak lepas dari penyediaan sarana berupa software dan hardware yang memiliki kecepatan proses yang sebanding dengan tingkat pekerjaan, serta penyediaan brainware / pengguna (user) / sumber daya manusia yang menjalankan sistem tersebut, agar peningkatan sistem tidak menjadi sia-sia karena ketidakmampuan usernya.

Perguruan Tinggi Raharja merupakan salah satu Perguruan Tinggi yang mengedepankan teknologi, sehingga segala sesuatu yang ada di dalamnya selalu berhubungan dengan teknologi salah satunya dalam pengontrolan kualitas barang teknik. Barang-barang yang digunakan disana sudah tergolong bagus namun masih diperlukan adanya sebuah sistem yang dapat memantau kualitas dari barang-barang teknik yang digunakan tersebut.

Quality Control Barang merupakan suatu cara mengendalikan kualitas, fungsi dan kegunaan suatu barang agar dapat berfungsi sebagaimana mestinya sehingga dapat menunjang dalam memberikan informasi atau pelaporan khususnya pada Bagian Teknik. Namun kendala yang ada saat ini adalah belum tersedianya suatu program khusus untuk memantau kualitas barang tersebut.Dalam penelitian akan memaparkan pokok permasalahan yang berhubungan dengan Quality Control Barang sehingga dapat menunjang pelaporan pada Bagian Teknik dengan menggunakan program PHP dan MySQL.

\subsection{Diagram Alur Penelitian}

\section{METODE PENELITIAN}

Mengenai metodelogi yang digunakan oleh penulis dalam melakukan peneletian ini. Metodelogi merupakan gambaran dan urutan pengerjaan yang digunakan dalam penelitian, diharapkan akan mendeskripsikan sistem pengembang pengolahan data informasi barang pada bagian teknik.

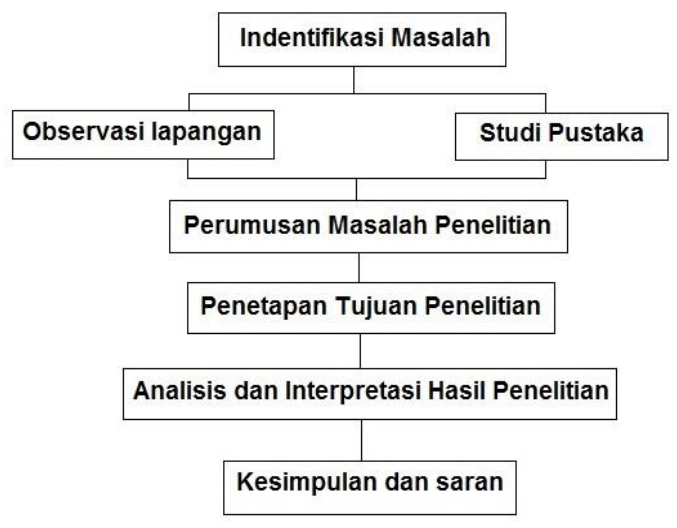

Gambar 1. Diagram Alir Metodologi Penelitian

Identifikasi masalah dilakukan untuk mengetahui gambaran permasalahan yang terjadi di tempat penelitian yang selanjutnya menjadi dasar dilakukannya penelitian ini. Proses identifikasi dilakukan dengan cara pengamatan dan wawancara dengan staf manajemen Perguiruan Tinggi Raharja. Dari hasil identifikasi masalah, Dalam pengolahan data bagian teknik masih belum dapat memberikan layanan terbaik untuk memenuhi kebutuhan informasi pada manajemen Perguruan Tinggi Raharja .

\subsection{Perumusan Masalah Penelitian}

Setelah dilakukan identifikasi permasalahan, maka permasalahan yang dapat dirumuskan dalam penelitian ini adalah bagaimana menganalisis sistem pengolahan data 
informasi barang yang berkualitas dapat terkontrol secara baik pada bagian teknik ,namun saat ini masih belum dapat memberikan informasi pelaporan terbaik untuk memenuhi kebutuhan informasi strategis yang diperlukan untuk mendukung pelaporan pada manajemen Perguruan Tinggi Raharja.Oleh karna itu di dapat rumusan masalah yang dapat diteliti, diantaranya:

a. Bagaimana caranya mengontrol barang inventaris dengan baik ?

b. Bagaimana merancang sistem Quality Control Barang yang baik sehingga informasi yang didapat dapat menunjang pelaporan pada bagian Teknik ?

\subsection{Analisis dan Interpretasi Hasil Penelitian}

Dari pengujian dalam pengolahan data bagian teknik yang ada ternyata masih banyak data yang di catat secara manual oleh bagian teknik, oleh karna sistem pelaporan data di bagian teknik tidak mencangkup ke seluruhan inventaris data barang yang tidak terkontrol secara baik, menyebabkan pelaporan data tidak terselesaikan dengan baik dan tetap waktu. Untuk itu perlu pengembangan sistem Aplikasi yang dapat menampung semua sistem pengolahan data informasi barang yang berkualitas dapat terkontrol secara baik pada bagian teknik dalam mengelolah pelaporan data yang diberikan kepada manajemen Perguruan Tinggi Raharja.

\subsection{Pengacuan Pustaka}

Ellen Yunita Puspitasari dkk.(2015) Penelitiannya menghasilkan Rancangan sistem pengendalian mutu dilakukan dengan membuat karakteristik kualitas, lembaran pipi, dan instruksi kerja, yang diperoleh dengan mengamati langsung pada proses produksi, dan wawancara dengan anggota perusahaan. Disarankan sistem kendali mutu telah diverifikasi oleh perusahaan dan dapat dilihat di Rencana mutu..[1]

Penelitian sejenis juga dikembangkan Deni Mahdiana (2011)Dengan adanya Sistem Informasi Manajemen Analisis dan desain sistem pengadaan barang diharapkan dapat membantu bagian pengadaan PT. Liga Indonesia untuk mempercepat proses pengolahan data, dan pencetakan laporan sehingga kelemahan dalam sistem yang lama dapat teratasi dan juga menanggulangi kesalahan-kesalahan yang dilakukan oleh manusia (human error).[2]

Arisandy Ambarita, (2016) Dinas Pendapatan dan Pengelolaan Aset Daerah Provinsi Maluku Utara merupakan salah satu instasi Pemerintahan dibidang pajak yang pengelolaan data asetnya, terutama yang berkaitan dengan kegiatan administrasi pelaporan, penerimaan, dan data pengelolaan aset masih bersifat konvesional, Mengingat pentingnya pengengelolaan data aset pada Dinas Pendapatan dan Pengelolaan Aset Daerah Provinsi Maluku Utara untuk meningkatkan kualitas dalam pelayananan data pendapatan, salah satunya di lakukan perbaikan manajemen dan teknologi Informasi berupa komputer adalah perangkat paling handal dan akurat untuk mendukung kerja sumber daya manusia dalam tugas manajemen Penelitian ini bertujuan Untuk Mengidentifikasi permasalahan yang ada pada system yang berjalan agar dapat membantu dalam merancang dan mengembangkan pengelolaan data aset yang lebih efektif dan akurat,.[3]

Aprilia Makisurat,dkk (2014) Penelitiannya bertujuan untuk mengetahui bagaimana penerapan sistem pengendalian intern untuk persediaan pada CV. Multi Media Persada Manado, sehingga mendapatkan gambaran yang jelas mengenai pengendalian intern persediaan barang dagangan yang telah diterapkan. Metode penelitian yang digunakan adalah metode deskriptif yaitu dengan melakukan wawancara langsung kepada karya wan perusahaan. Penelitian ini dilakukan pada CV. Multi Media Persada Manado yang merupakan salah satu jenis perusahaan dagang. Hasil penelitian pada CV. Multi Media Persada Manado atas pengendalian intern sudah baik, karena telah menerapkan unsur-unsur pengendalian intern. Disarankan pihak manajemen dapat melakukan pencatatan manual serta menyediakan staf ahli dalam menilai kualitas barang dagangan.[4]

Willy Riyadi (2015) CV. Agung Baru Sejahtera Jambi merupakan salah satu perusahaan yang memanfaatkan sistem informasi dalam menunjang proses bisnis yang dilakukannya guna menyimpan dan mengelola data tentang persediaan barang, data pelanggan, data pembelian, data penjualan, data keuangan dan pajak. Selama ini, kegiatan perusahaan beberapa kali 
mengalami kendala/masalah pada sistem informasi perusahaan yang sangat menggangu kegiatan dan proses bisnis perusahaan. Oleh karena itu, penelitian ini bertujuan mengukur risiko Sistem Informasi (SI) perusahaan CV. Agung Baru Sejahtera (ABS) Jambi dengan memanfaatkan COBIT (Control Objectives for Information and Related Technology) framework dan kuesioner maturity level serta gap analysis guna mengidentifikasi risiko, analisa risiko, respon risiko dan evaluasi risiko.[5]

\section{HASIL DAN PEMBAHASAN}

Setelah prosedur sistem yang diusulkan selesai dijabarkan, maka prosedur tersebut akan digambarkan kedalam bentuk diagram agar dapat mudah dibaca.

\subsection{Implementasi dengan Diagram UML}

a. Usecase Diagram

Use Diagram Usulan dapat dilihat dari gambar dibawah ini .

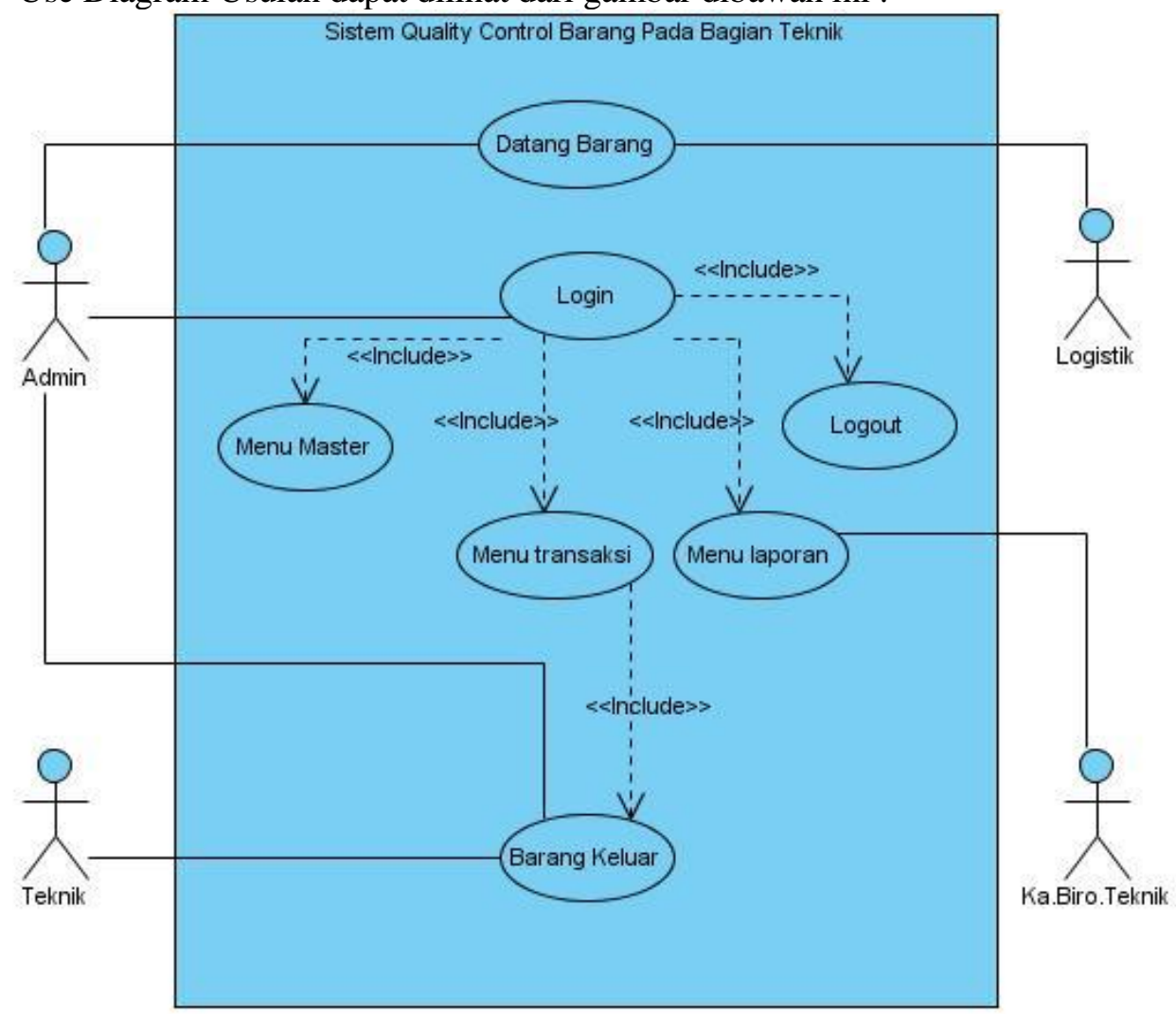

Gambar 2. Use Case Diagram Quality Control Barang yang Diusulkan

Berdasarkan gambar 1. yang diusulkan terdapat :

a. 1 (system) mecakup seluruh kegiatan Monitoring Quality Control Barang.

b. Terdapat 4 (tiga) Actor, yang melakukan kegiatan diantaranya : Admin, Teknik,Logistik dan Kabiro.teknik

c. Terdapat 7 (Tujuh) Use Case utama yaitu : Login, Data Barang, Menu Master, Menu Transaksi, Menu laporan, Barang Keluar, logout. 


\section{b. Class Diagram}

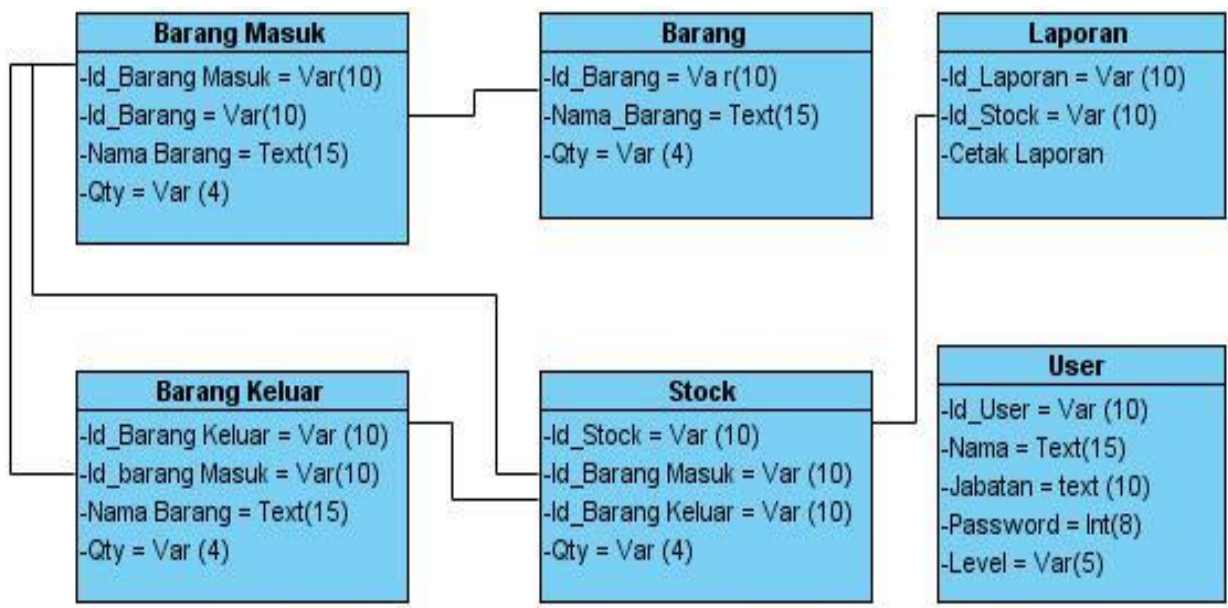

Gambar 3. Class Digram Sistem yang Diusulkan

Berdasarkan gambar 3. class diagram sisitem yang diusulkan terdapat :

a. 6 (enam) class, himpunan dari objek-objek yang berbagai atribut serta diantraranya tbl_user, tbl_Stock, tbl_Barang_Masuk, tbl_Barang_Keluar, tbl_Barang, tbl_Laporan, tbl_Stock.

b. Terdapat 5 (Lima) multiciply hubungan anara objek satu dengan objek lainya.

\subsection{Hasil Tampilan Aplikasi}

\section{a.Halaman Home User}

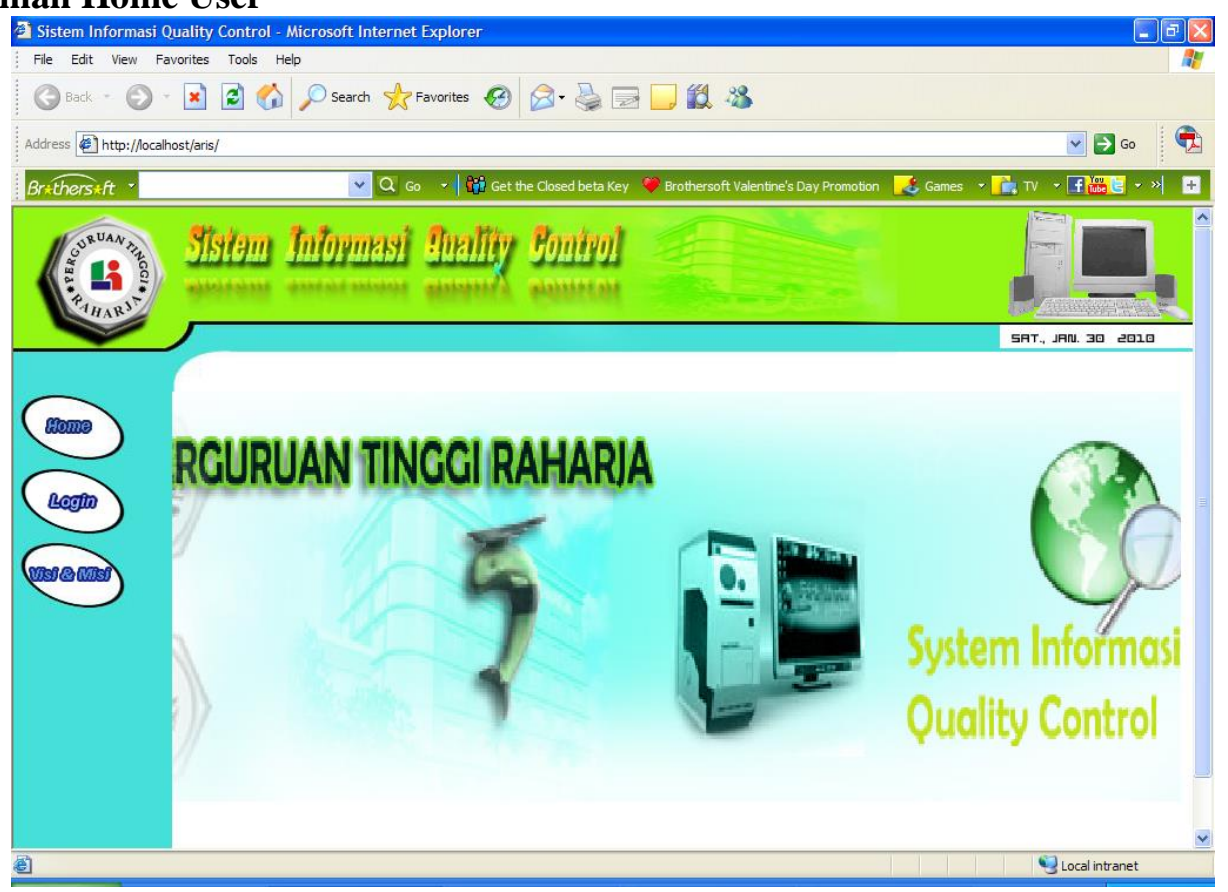

Gambar 4. Halaman Home User

Pada gambar 4 merupakan halaman Home User, ini akan muncul pertama kali saat mengakses web ini secara online. Pada halaman ini, terdapat menu-menu untuk user yaitu Home, Login, dan Visi\&Misi. 


\section{b.Halaman Visi \& Misi}

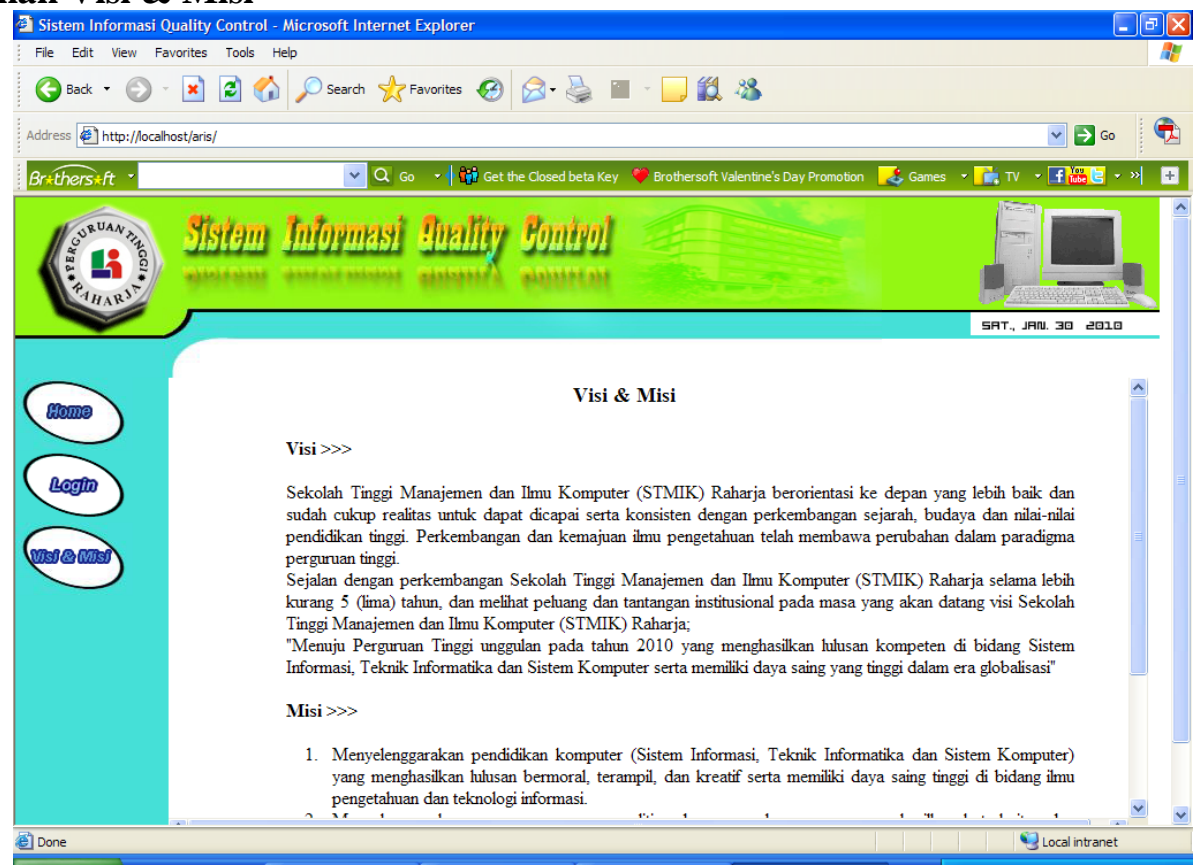

Gambar 5. Tampilan Halaman Visi \& Misi

Pada Gambar 5, menampilkan user masih bisa membuka Halaman home yang berisikan Visi \& Misi dari Perguruan Tinggi Raharja.

\section{c.Halaman Admin}

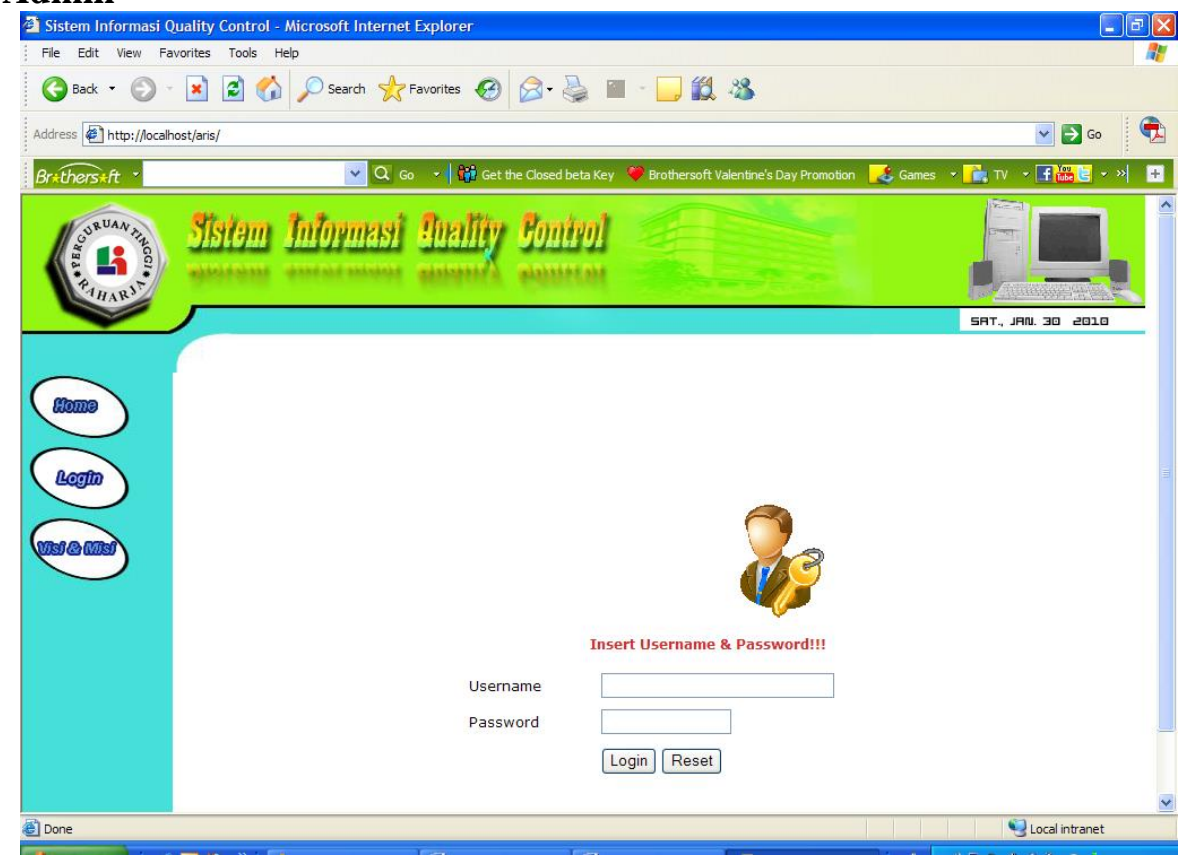

Gambar 6. Tampilan Halaman Admin

Dan pada Gambar 6, yaitu menampilkan Login dilakukan di Halaman Admin, pada saat admin ingin login harus terlebih dahulu masuk ke area administrator dengan terlebih dahulu mengisikan password.

\section{d. Halaman Home Admin}




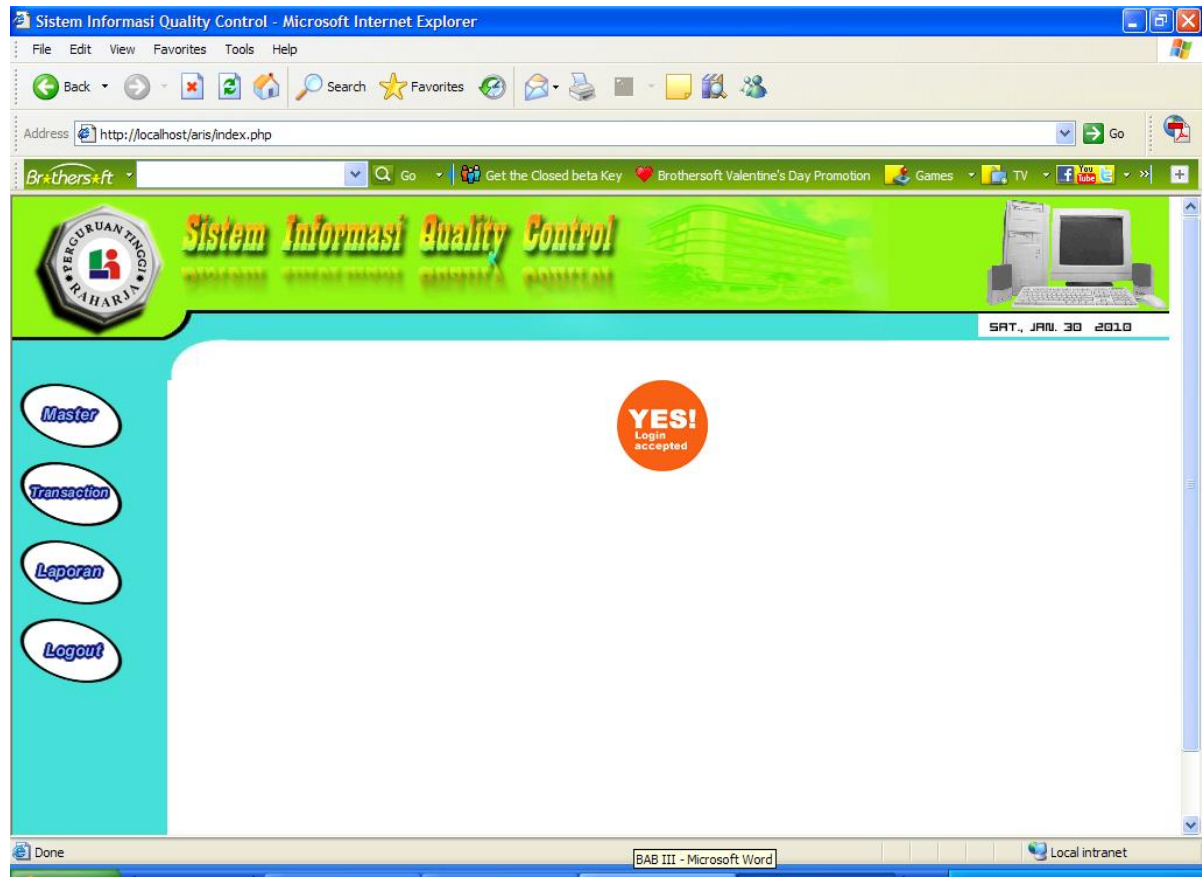

Gambar 7. Tampilan Halaman Home Admin

Pada gambar 7 juga menampilkan menu user login pada halaman Admin, maka user dapat mengakses beberapa proses di halaman home admin yang terdiri dari beberapa menu pilihan.

\section{e.Tampilan Master}

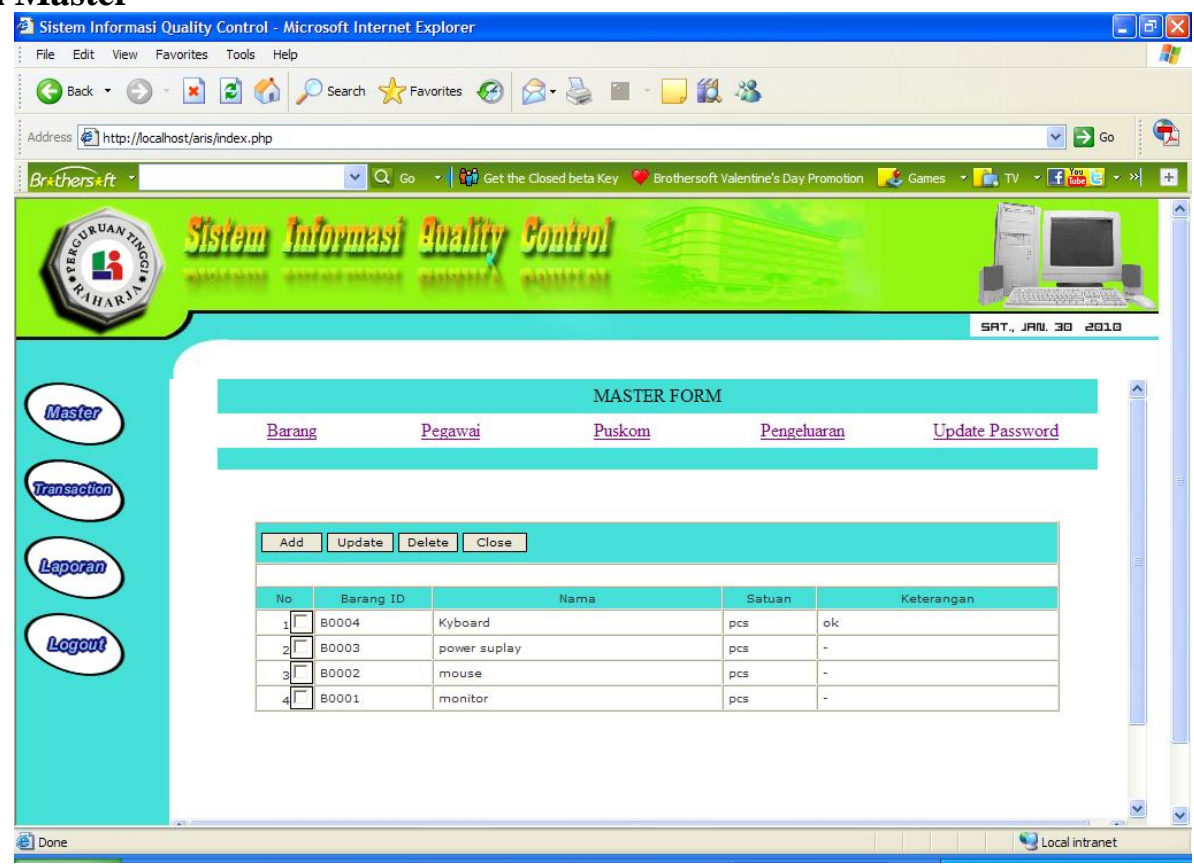

Gambar 8. Tampilan Halaman Master

Padagambar 8, menampilkan Halaman ini User harus melakukan penginputan data dari awal semua transaksi yang dilakukan diform master. 


\section{f.Tampilan Transcation}

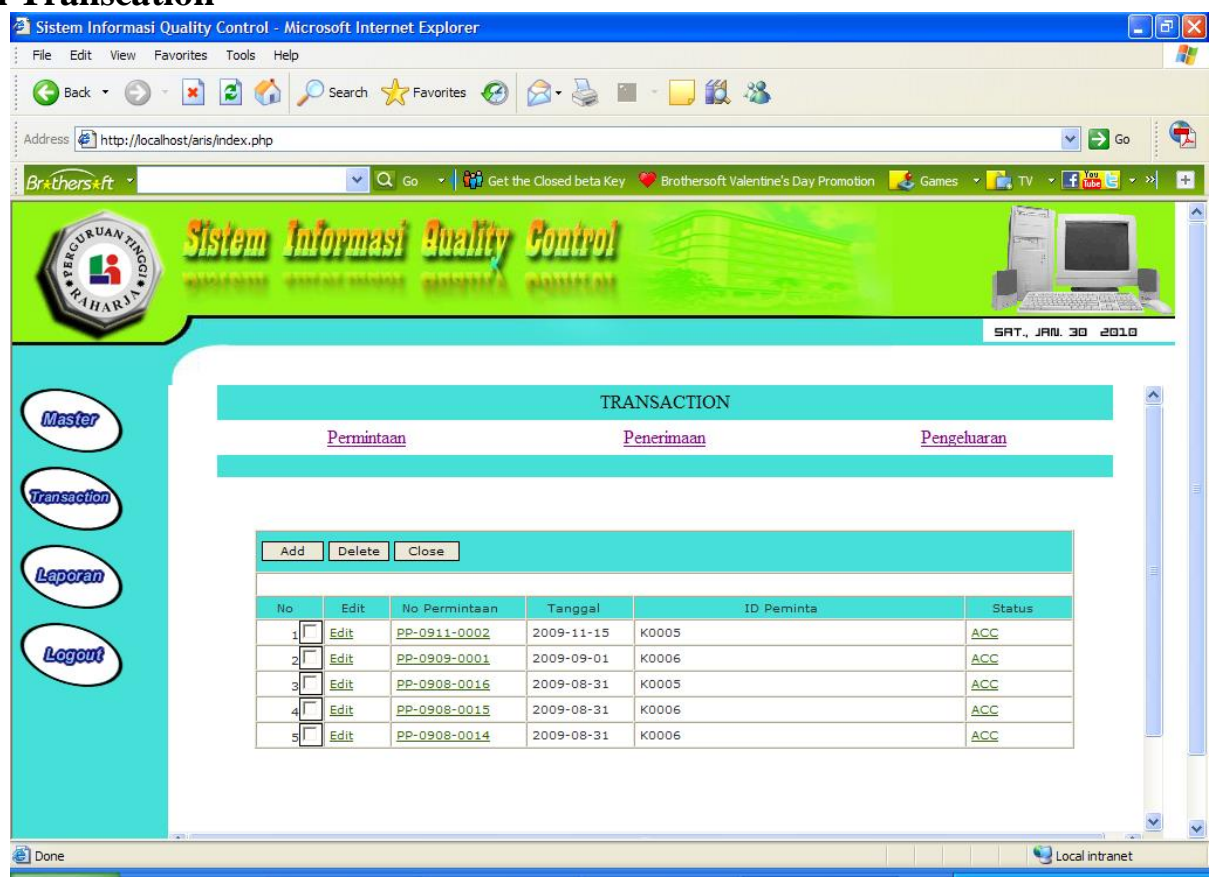

Gambar 9. Tampilan Halaman Transaction

Pada gambar 9 menampilkan halaman ini berisikan tentang semua transaksi yang dilakukan mulai dari permintaan, barang masuk,barang keluar dan stock.

\section{g. laporan}

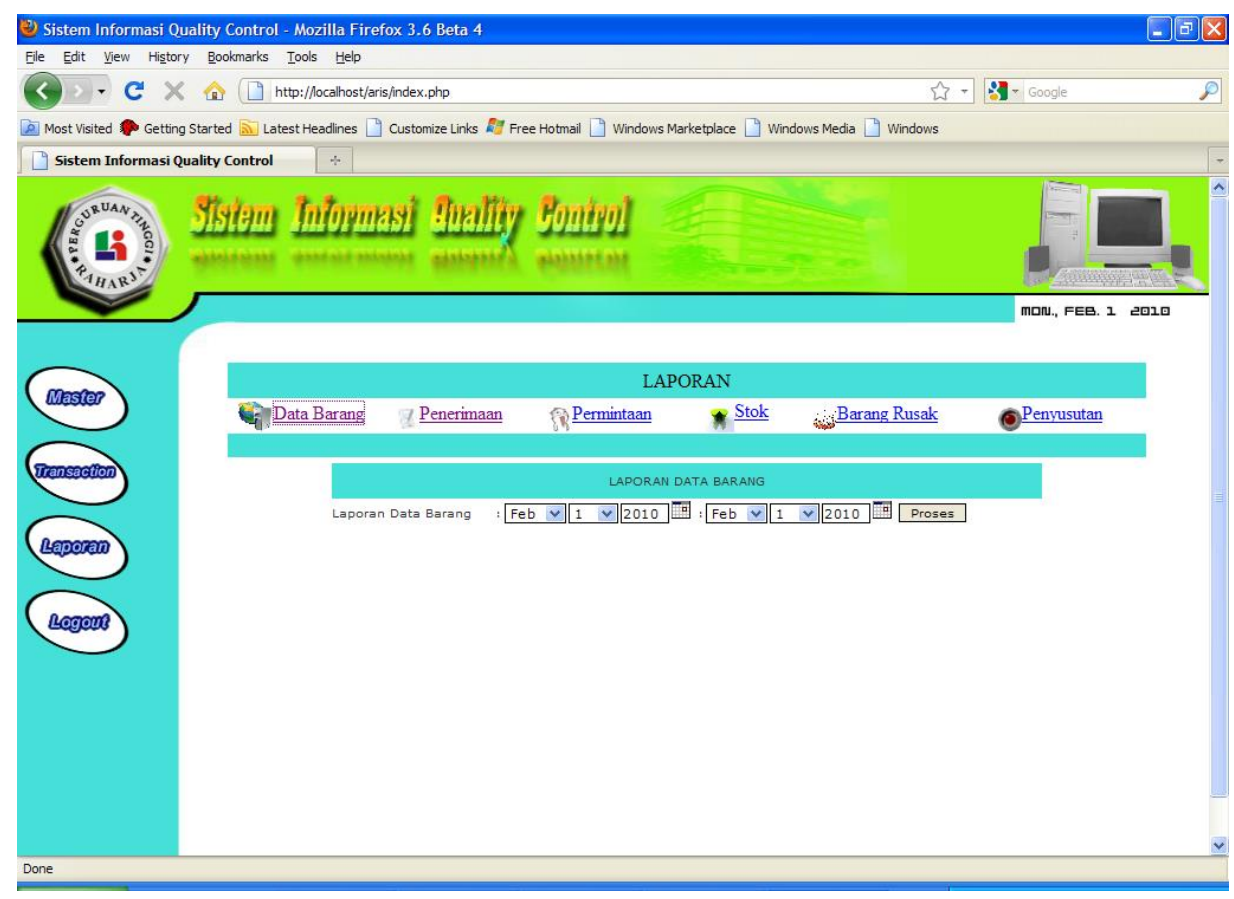

Gambar 10. Tampilan Halaman Laporan

Pada gambar 10, menampilkan Halaman laporan ini semua berisikan laporan-laporan dari semua transaction, dapat dilihat sesuai tanggal, bulan, dan tahun. 


\section{KESIMPULAN}

Pada kesimpulannya alpikasi sistem informasi couality control barang pada bagian teknik Perguruan Tinggi Raharja , memiliki kelebihan dan kekurangannya, serta kemungkinan pengembangan selanjutnya adalah sebagai berikut :

1. Pemakai (Admin) melakukan browsing ke website di Internet expoler maupun Mozilla Firefox, dan mengetikan alamat websitenya karna ini online dan web disimpan disatu komputer server.

2. Adapun data-data yang ada pada website Sistem Informasi Coulity Control ini hanya dapat di input oleh seorang admin webnya.

3. Admin akan melakukan inputan data baru dengan masuk ke Halaman Menu Admin.Dan diarea administrator dengan terlebih dahulu mengisikan password.

4. Setelah masuk ke halaman Home Admin maka admin akam melakukan beberapa transaksi sesuai kebutuhan di antaranya ada menu Master, Menu Transactin dan Menu laporan.

5. Data-data yang ada pada website Sistem Informasi Coulity Control hanya dapat dilihat oleh Admin dan Kabiro Teknik.Untuk secara Fullcontrol penginputan hanya Admin, Sedangkan untuk KaBiro Teknik harus juga Login dengan passwornya tapi hanya dapat melihat laporan-laporan saja tidak bisa melakukan pengeditan.

6. Dan Jika sewaktu-waktu ada data yang harus diedit atau adanya data terbaru pada Website Sistem Informasi Coulity Control barang pada bagian teknik di perguruan Tinggi Raharja,maka data-data yang sudah ada bisa diedit atau diperbaharui oleh Admin yang mempunyai hak akses.Misalnya ada penginputan data barang baru.

7. Di dalam implementasi suatu aplikasi juga diperlukan suatu proses pengendalian dan perawatan terhadap aplikasi yang sedang berjalan. Pengendalian dilakukan untuk antisipasi apabila terjadi sesuatu hal yang tidak diinginkan. Pengendalian bisa dilakukan baik secara fisik maupun secara data. Secara data bisa dilakukan dengan cara membatasi user yang boleh melakukan akses terhadap aplikasi. Hanya user yang diberi hak akses saja yang bisa login kedalam aplikasi.

Selain dengan pembatas akses, hal yang perlu dilakukan adalah melakukan back up rutin terhadap data. Back up yang baik disimpan kedalam suatu tempat yang terpisah. Hal ini bertujuan agar back up yang kita lakukan tidak mengalami kerusakan apabila terjadi masalah pada fisik

\section{SARAN}

Berdasarkan uraian pada Penelitian ini, maka penerapan desain sistem yang terintegrasi untuk pengontrolan barang pada bagian Teknik ini dapat menjawab perumusan maslah yang terjadi dengan terwujud sistem ini, yaitu, :

1. Proses pengontrolan data barang inventaris saat ini sudah berjalan sepenuhnya terkomputerisasi.dan backup data harus di lakukan.

2. Sistem yang dibangun nantinya dapat memantau barang-barang Teknik agar dapat dipergunakan sebagaimana mestinya sehingga dapat menunjang dalam memberikan informasi atau pelaporan khususnya pada bagian Teknik secara online.

\section{DAFTAR PUSTAKA}

[1] Ellen Yunita Puspitasari,dkk (2015), Perancangan Sistem Pengendalian Kualitas di PT X, Jurnal Titra, Vol. 3, No. 2, Juli 2015, pp. 229-234,Portal Garuda.

[2] Deni Mahdiana (2011), Analisa Dan Rancangan Sistem Berorientasi Obyek: Studi Kasus PT.Liga Indonsia, Vol.3 No.2, Universitas Budi Luhur .Jakarta

[3] Arisandy Ambarita,(2014), Analisis Pengembangan Sistem Informasi Pengolahan Aset Dearah (Studi Kasus : Dinas Pendapatan dan Pengelolaan Aset Daerah Provinsi Maluku Utara),Journal IJNS, Vol 5, No 4, Maluku Utara 
[4] Aprilia Makisurat,dkk (2014), Penerapan Sistem Pengendalian Intern Untuk Persediaan Barang Dagang Barang Dagangan Pada CV.Multi Median Persada manado. Jurnal Emba,Vol 2 :No 2 , ejournal.unsrat.ac.id

[5] Willy Riyadi,(2015), Analisis Risiko Sistem Informasi perusahaan Dengan control Objectives for Information And Related Technologi (Cobit) framework (Studi Kasus : Cv.Agung Baru Sejahtera Jambi), JURNAL ILMIAH MEDIA SISFO, Vol 9 No 2 (2015),Jambi

[6] Taufiq, rahmat, Sistem informasi menejemen konsep dasar analisa dan metode pengembangan, graha ilmu : yogyakarta, 2014.

[7] Raharjo, Budi. Belajar Otodidak Membuat Database Menggunakan MySQL.Informatika :Bandung. 2015

[8] Rocky Aji Wibowo, "Sistem Informasi Persediaan Keluar Masuk Barang Pada Inside Distro Jakarta," ejournal portal Speed - Sentra Penelitian Engineering dan Edukasi, vol. 1, no. 4, 2013.

[9] Hartati Deviana, "Penerapan XML Web Service Pada Sistem Distribusi Barang,"portal garuda,vol.6, no. 2, 2014.

[10] Mita Rohayati, "Membangun Sistem Informasi Monitoring Data inventory Di Vio hotel indonesia," Jurnal Ilmiah Komputer dan Informatika (KOMPUTA), vol. 1, no. 1, februari 2014.

[11] Rika Yunitarini, "Rancang bangun sistem agen cerdas monitoring stok perusahaan," Jurnal Ilmiah KURSOR, vol. 5, no. 1, Januari 2014. 